\title{
COLON CARCINOMA: A CADVERIC CASE REPORT
}

\section{Sharadkumar Pralhad Sawant *1, Shaheen Rizvi ${ }^{2}$.}

${ }^{* 1}$ Professor and Head, Department of Anatomy, K. J. Somaiya M edical College, Somaiya Ayurvihar, Eastern Express Highway, Sion, Mumbai, India.

${ }^{2}$ Assistant Lecturer, Department of Anatomy, K. J. Somaiya M edical College, Somaiya Ayurvihar, Eastern Express Highway, Sion, Mumbai, India.

\section{ABSTRACT}

During routine dissection, of 70 year old donated embalmed male cadaver in the Department of Anatomy, at K.J. Somaiya M edical College, Sion, M umbai, India, a hard bulge was observed in the distal part of descending colon. On incising, a mass was observed in its posterior wall. It measured $5 \mathrm{~cm} \times 5 \mathrm{~cm}$ encircling nearly half the lumen but not showing any signs of obstruction. Histopathology confirmed the diagnosis of adenocarcinoma.

Colorectal cancer (CRC) is the fourth most common malignant neoplasm in the world, and also the most frequent in the digestive tract, presenting with high mortality rates. Cancers on the right side of the large intestine (ascending colon and caecum) tend to be exophytic and rarely causes obstruction while left-sided tumors tend to be circumferential and can obstruct the bowel lumen. $90 \%$ cancers are adenocarcinomas which is a malignant epithelial tumor, originating from superficial glandular epithelial cells lining the colon and rectum. Likelihood of cure is greater when disease is detected at early stage. Early detection and screening is of pivotal importance. Colonoscopy detects some colon polyps and cancers early enough that they may be treated.

KEYWORDS: Hard Bulge, Descending Colon, Adenocarcinoma, Colorectal Cancer, Malignant Neoplasm, Colonoscopy.

Address for Correspondence: Dr. Sharadkumar Pralhad Sawant, 25/2, Samrat Ashok Nagar Society, Shell Colony Road, Chembur, M umbai - 400 071, Maharashtra, India.

Telephone no.: 9322061220, 022-25275775, Fax no.: 022 - 24091855

E-Mail: drspsawant@gmail.com, sharad@somaiya.edu

\section{Access this Article online}

\section{Quick Response code}

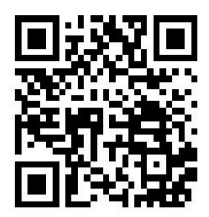

DOI: $10.16965 /$ ijar.2017.277

Web site: International Journal of Anatomy and Research

ISSN 2321-4287

www.ijmhr.org/ijar.htm

Received: 31 M ay 2017

Peer Review: 01 Jun 2017

Revised: None
Accepted: 21 June 2017

Published (0): 30 Jun 2017

Published (P): 30 Jun 2017

\section{INTRODUCTION}

The colon consists of four regions including the ascending colon, transverse colon, descending colon, and sigmoid colon. The descending colon is that part of the large intestine which extends from the splenic flexure to the beginning of the sigmoid colon. It begins at the splenic flexure at the upper left part of the abdomen. It passes downward through the left hypoc hondrium and lumbar regions, along the outer border of the left kidney and end at the lower left part of the abdomen where it is continues as the sigmoid colon. It is retroperitoneal. The arterial supply comes via the left colic artery The function of the descending colon in the digestive system is to store the remains of digested food or waste that will be emptied into the rectum. The stools gradually solidify as they move along into the descending colon [1].

There are several diseases associated with the descending colon. Among the most common are the inflammatory bowel diseases (such as 
ulcerative colitis or Crohn's disease) and colon cancer.

Colorectal cancer (CRC) is the third most common cancer worldwide. Approximately $56 \%$ of patients with CRC die from their cancer [2].

\section{CASE REPORT}

During routine dissection, of 70 year old donated embalmed male cadaver in the Department of Anatomy, at K.J. Somaiya M edical College, Sion, M umbai, India, a hard bulge was observed in the distal part of descending colon. Meticulous dissection was carried out to separate the descending colon from the posterior abdominal wall. The wall of the colon was then incised carefully. On incising, a mass was observed in its posterior wall. It measured $5 \mathrm{~cm} \times 5 \mathrm{~cm}$ encircling nearly half the lumen but not showing any signs of obstruction. This was indicated by the presence of fecal matter distal to it. Histopathology confirmed the diagnosis of adenocarcinoma. The rest of the colon was normal. The photograph of the mass was taken for proper documentation.

On obtaining a family history from the cadaver's next of kin, he was found to be suffering from bleeding per rectum off and on, pain in abdomen and a change in bowel habits since the past six months. He also exhibited around $5 \mathrm{~kg}$ weight loss, but had refused any sort of investigation.

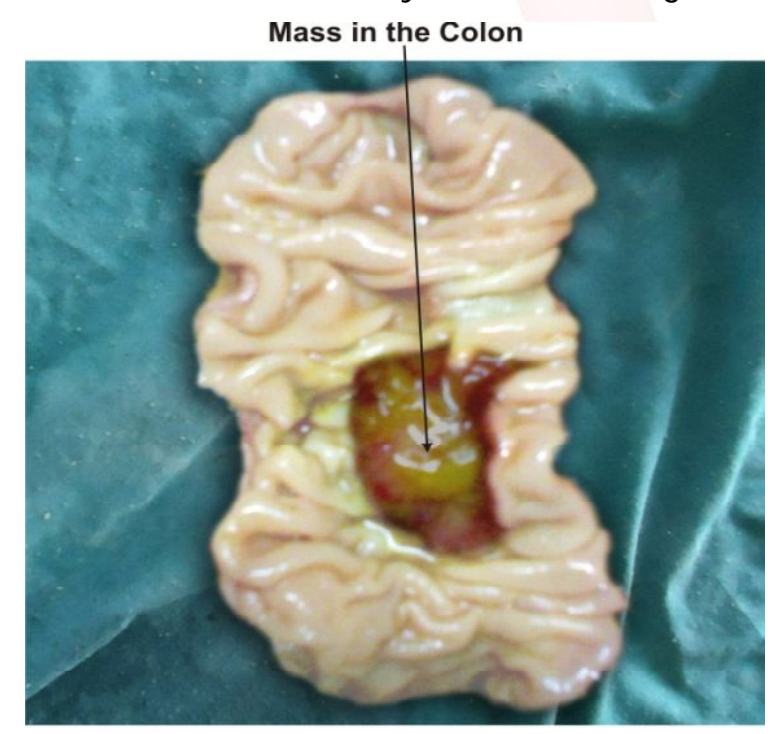

DISCUSSION

Colorectal cancer (CRC) is the fourth most common malignant neoplasm in the world, and also the most frequent in the digestive tract, presenting with high mortality rates - about half a million deaths per year. It is a leading cause of death in the elderly and about $20 \%$ of these patients present metastasis at diagnosis, most often in the liver. Young patients have more aggressive disease. Environmental causes include diet low in fiber and higher in fat. There is also some amount of a genetic factor involved [3]. Colorectal cancer originates in the lining of the colon and rectum. Cancers on the right side of the large intestine (ascending colon and caecum) tend to be exophytic, that is, the tumor grows outwards from one location in the bowel wall. This very rarely causes obstruction of feces, and presents with symptoms such as anemia. Left-sided tumors tend to be circumferential, and can obstruct the bowel lumen, much like a napkin ring, and results in thinner caliber stools. Colon cancers arise from abnormal cell development usually in the form of polyps. Polyps on the inner lining of the large intestine or rectum start as benign and can progress into 2 malignant tumors. These tumors can metastases throughout the body into vital organs inhibiting proper function [4].

According to Andrade and Pereira, adenocarcinomas are responsible for $90 \%$ of the CRC cases. They arise from adenomas (villous adenoma has higher malignant potential). Adenomatous polyps are considered a precancerous condition. When polyps become malignant they spread from the lining of the colon through blood vessels or lymph vessels, which can metastasize to distal areas such as the liver and lungs [5].

Adenocarcinoma is a malignant epithelial tumor, originating from superficial glandular epithelial cells lining the colon and rectum. It invades the wall, infiltrating the muscularis mucosae layer, the submucosa, and then the muscularis propria. Tumor cells describe irregular tubular structures, harboring pluristratification, multiple lumens, reduced stroma ("back to back" aspect). Sometimes, tumor cells are discohesive and secrete mucus, which invades the interstitium producing large pools of mucus. This occurs in mucinous adenocarcinoma, in which cells are poorly differentiated. If the mucus remains inside the tumor cell, it pushes the nucleus at the periphery, this occurs in "signet-ring cell." Depending on glandular architecture, cellular 
pleomorphism, and mucosecretion of the predominant pattern, adenocarcinoma may present three degrees of differentiation: well, moderately, and poorly differentiated $[6,7]$.

Common metastatic sites other than liver include: lung, bone and brain. Isolated splenic metastases are rare, and they are usually a sign of widespread disease. There is a notable difference between the proximal and distal colon, in metastases, clearly demonstrating their different biology. The proximal colon originates from the midgut, whereas the distal colon stems from the hindgut. The two entities vary in e.g. epidemiology, biology, and genetics [8].

Colon cancer is said to be a "stem cell disease" because neoplastic cells within a carcinoma have regenerative growth capabilities and they produce additional abnormal cells. "Cancer stem cells possess high levels of ATP-binding cassette $(A B C)$ transporters and antiapoptotic molecules, active DNA repair, slow replication capacities and they produce growth factors that confer refractoriness to antineoplastic treatments. The inefficiency of conventional therapies toward the stem cell population might explain cancer chemoresistance and the high frequency of relapse shown by the majority of tumors." Cancerous tumors elude destructive signals from therapeutic drugs because most drug therapies, including chemo, target rapidly differentiating cancer cells while overseeing the slowly dividing ones. This oversight is due to disruption in cellular pathways that control proliferation, differentiation, and apoptosis making cancer stem cells harder to pinpoint and destroy [9].

Colonoscopy is one of the colorectal cancer screening tests available. Colonoscopy screening prevents approximately two thirds of the deaths due to colorectal cancers on the left side of the colon, by detecting some colon polyps and cancers early enough that they may be treated [10]. Colorectal Cancer Survival (Dukes Stages, 5y): Stage A: limited to mucosa and submucosa - $90 \%$ Stage B: extends into muscularis or serosa - $60-75 \%$ Stage C: one positive node $69 \%$ six or more positive nodes - $27 \%$ Stage D: metastasis. to liver, bone, lung - 5\% [11].

Diagnosis and treatment vary depending on the type and location of colorectal cancer. Surgical Int J Anat Res 2017, 5(2.3):4020-23. ISSN 2321-4287 resection is the only curative treatment. Likelihood of cure is greater when disease is detected at early stage. Early detection and screening is of pivotal importance [12].

\section{CONCLUSION}

Colorectal cancer (CRC) is the third most common cancer worldwide. Colorectal cancer originates in the lining of the colon and rectum from abnormal cell development usually in the form of polyps. Adenocarcinomas are responsible for $90 \%$ of the CRC cases. When polyps become malignant they spread from the lining of the colon through blood vessels or lymph vessels, which can metastasize to distal areas such as the liver and lungs. Colon cancer is said to be a "stem cell disease". Colonoscopy detects some colon polyps and cancers early enough that they may be treated.

\section{ACKNOWLEDGEM ENTS}

Authors are thankful to Dean Dr. Vinayak Sabnis Sir for his support and encouragement. Authors are also thankful to M r. M. M urugan for his help. Authors also acknowledge the immense help received from the scholars whose articles are cited and included in references of this manuscript. The authors are also grateful to authors / editors / publishers of all those articles, journals and books from where the literature for this article has been reviewed and discussed.

\section{Conflicts of Interests: None}

\section{REFERENCES}

[1]. Moore K.L, A.F.Dalley 2006, Clinically oriented anatomy 2006, $5^{\text {th }}$ Ed, Lipincott; Williams and Wilkins Baltimore.

[2]. Griffin-Sobel, J. (2007) Gastrointestinal Cancers. USA; ONS.

[3]. Lee, G. H. et al. Is right-sided colon cancer different to left-sided colorectal cancer? - a systematic review. European journal of surgical oncology: the journal of the European Society of Surgical Oncology and the British Association of Surgical Oncology 2015;41:300-308, 10.1016/j.ejso.2014.11.001.

[4]. G Launoy et al. Proximal and Distal Cancers of the Colon: 2 Epidemiologically Different Cancers, Gastroenterol Clin Biol. 1989;13(3):255-259.

[5]. Andrade SM S, Pereira FL. Câncer colorretal sincrônico - relato de caso e revisão de literatura.J Coloproctol 2007;27(1):69-79. 
[6]. 'Colon cancer, medline plus, medical encyclopedia' US national library of medicine US; national library of medicine n.d.web 22 April 2014; https:// www.nim.nih.gov/ medline plus/ency/article/ 000262htm

[7]. 'Colorectal cancer overview'; colon cancer alliance n.d web 22 April 2014; https:// www.c.calliance.org/ colorectal cancer/overview.htm

[8]. Riihimäki, M. et al. Patterns of metastasis in colon and rectal cancer. Sci. Rep. 2016;6:29765; doi: 10.1038/srep29765.

[9]. Simone SDF, Mancuso P, Benfante A, et al. Colon cancer stem cells: bench to bedside new therapeutic approaches in clinical oncology for disease breakdown, Cancers.2011;3:1957-1974.
[10]. olff WI, Shinya H. Earlier diagnosis of cancer of the colon through colonic endoscopy (colonoscopy)". Cancer. 1974;34 (Supplement S3): 912-931.

[11]. Braccia, D.P. \& Heffernan, N. Surgical \& Ablative Modalities for the Treatment of Colorectal Caner M etastatic to the Liver. Clinical Journal of Oncology Nursing 2003;7(2):178-184.

[12]. Wilkes G. Therapeutic options in the management of colon cancer: 2005 update. J Clin Oncol 2005;9:31-44.

How to cite this article:

Sharadkumar Pralhad Sawant, Shaheen Rizvi. COLON CARCINOMA: A CADVERIC CASE REPORT. Int J Anat Res 2017;5(2.3):4020-4023. DOI: 10.16965/ijar.2017.277 